\title{
Price estimation and economic evaluation of the production cost of red wines produced by immobilized cells on dried raisin berries
}

This article was published in the following Dove Press journal:

International Journal of Wine Research

8 February 201 I

Number of times this article has been viewed

\author{
Argiris Tsakiris' \\ Kiriaki Sotirakoglou ${ }^{2}$ \\ Panagiotis Kandylis ${ }^{3}$ \\ Panagiotis Kaldis' \\ Constantina Tzia ${ }^{4}$ \\ Yiannis Kourkoutas ${ }^{3}$ \\ 'Department of Oenology \\ and Beverage Technology, Faculty \\ of Food Technology and Nutrition, \\ Technological Educational Institute \\ of Athens, Athens, Greece; \\ ${ }^{2}$ Department of Mathematics \\ and Statistics, Agricultural \\ University of Athens, Athens, Greece; \\ ${ }^{3}$ Applied Microbiology and Molecular \\ Biotechnology Research Group, \\ Department of Molecular Biology \\ and Genetics, Democritus University \\ of Thrace, Alexandroupolis, Greece; \\ ${ }^{4}$ Laboratory of Food Chemistry \\ and Technology, School of Chemical \\ Engineering, National Technical \\ University of Athens, Athens, Greece
}

Correspondence: Yiannis Kourkoutas Applied Microbiology and Molecular Biotechnology Research Group, Department of Molecular Biology and Genetics, Democritus University of Thrace, Alexandroupolis GR-68100, Greece

Tel +30 255I0 30644

Fax +30 2551097243

Email ikourkou@mbg.duth.gr

\begin{abstract}
The aim of the study was initially to estimate the price of red wines produced by immobilized cells on dried raisin berries and subsequently to investigate whether the estimated price was sufficient to counterbalance the increased investment and operational costs required for industrial application of the novel biotechnological process. Price estimation of the experimental wines was based on the correlation of sensory quality, determined by a group of trained tasters, and the price of commercial wines available in a certain market. Application of principal component analysis (PCA) provided improved results over simple and exponential regression analysis, as only a part of the relationship between the two variables was represented $(68.4 \%$ and $75.3 \%$, respectively). However, with PCA the total variance explained by the two components was $100 \%$. Taste was more important than aroma in determining sensory quality, and wine price was mainly affected by sensory quality rather than wine age in the Greek market. The total increase of production cost was estimated to be $€ 0.032 /$ bottle, which is significantly lower than the increase of $€ 2.08 /$ bottle price estimated by PCA for the red wines produced by immobilized cells, due to the improved aromatic potential compared with wines produced by free cells. Hence, profit for the wine industry was estimated to be $€ 1.02$ /bottle.
\end{abstract}

Keywords: wine market, sensory quality, regression analysis, price, PCA

\section{Introduction}

In the past few years, there has been an upsurge of interest in the use of immobilized cell technology for wine making, due to the attractive technical and economic advantages compared with the conventional free cell system ${ }^{1,2}$ and to the improved quality. ${ }^{3-6}$

Wine quality is influenced by many and varying factors such as grape variety, ${ }^{7}$ wine-making techniques, ${ }^{8}$ proliferation of yeast microflora, ${ }^{9}$ and environmental and management practices. ${ }^{10}$ It is common sense that the improvement of wine quality is the principal aim in oenology research. Quality of experimental wines may be evaluated by blind comparative sensory tests from well-trained tasters based on objective criteria ${ }^{11}$ and further statistical analysis. ${ }^{12}$ The blind estimation is dependent only on sensory evaluation and not on other factors. On the contrary, wine quality for consumers depends on a high number of factors, one of which is sensory quality. According to Verdú Jover et al, ${ }^{13}$ wine quality also depends on extrinsic factors such as reputation, region, "appellation d'origine", and advertising, and on intrinsic factors such as age, harvest, alcohol content, variety, taste, aroma, and color. Wine quality even depends on price ${ }^{14}$ and awards assigned..$^{15}$ Several reports have clearly shown that individuals seem to highly appreciate a wine when it is believed to be of high cost. ${ }^{16,17}$ 
A relationship between wine quality and a product's price is vital from the consumer's point of view, as there is always a concern if the price corresponds to the product's quality. According to Teil, ${ }^{18}$ the opinion of critics, who have built wine reputation based on a large amount of records of quality, is very important in creating the relationship between price and quality. The relationship between wine price and wine quality appeals to hedonic pricing, where the price of a good is a function of its characteristics. Hedonic regression models using quality as a characteristic are common. ${ }^{19-25}$ However, the hedonic method applied to price-quality relationships in wine markets has been criticized by Unwin. ${ }^{26}$ Although many efforts have been made to apply a control method for assessing wine quality, ${ }^{27-32}$ correlation of sensory quality with chemical composition is still very difficult. Moreover, because economic studies usually downgrade the importance of sensory evaluation, they fail to explain such high differences in price for a product such as wine. Thus, oenological research is based exclusively on sensory evaluation, but the relationship between the quality of a wine and its price is still questionable.

Hence, the main objectives of the present study were to i) carry out a comparative study for estimation of the suitable price of the wines produced by immobilized yeast on dried raisin berries in a specific wine market by applying simple regression, exponential regression, and principal component analysis (PCA); ii) assign the main factors determining wine price and sensory quality; and iii) investigate whether the estimated price of the wines produced by the novel biotechnological process is adequate to counterbalance the increased investment and operation costs of the proposed technology.

\section{Materials and methods Experimental red wine making}

Dried Saccharomyces cerevisiae strain Uvaferme 299, which is widely used in industrial wine making, was used for wine fermentation. Cell immobilization on raisin berries was carried out as described previously. ${ }^{6}$

For red wine making, $150 \mathrm{~g}$ of the immobilized biocatalyst along with must ( $\approx 12.8$ Be density) produced from $300 \mathrm{~g}$ of red grapes of the Greek variety Agiorgitiko $(\approx 250 \mathrm{~mL})$ and skins obtained after crushing $300 \mathrm{~g}$ of grapes were introduced into a 1-L glass tower bioreactor. ${ }^{6}$ Two metal net constructions were attached to the bioreactor holding the immobilized biocatalysts of raising berries at the middle-bottom end of the bioreactor and skins immersed in the fermentation broth at the middle-top end of the bioreactor. Of note, the wines used in the present study derived from the fourth repeated batch fermentation. ${ }^{6}$ In parallel, batch wine fermentations were carried out with $\approx 15 \mathrm{~g}$ (wet weight) of free cells/L, so in both cases the same amount of initial yeast biomass was used $(\approx 9 \log \mathrm{cfu} / \mathrm{mL})$. Fermentations were carried out at $25^{\circ} \mathrm{C}$ until all sugar was utilized (about 4 days).

\section{Sensory evaluation}

Sensory evaluation of red wines produced by free and immobilized cells on raisin berries and of 15 commercial wines was carried out by 12 well-trained tasters. All panelists were students of the Department of Oenology and Beverage Technology at the Technological Educational Institute (TEI) of Athens, Greece, and had attended a 10-week course on "Organoleptic Estimation of Wines and Beverages". The panel was chosen from an initial group of 20 students based on their course scores. ${ }^{31}$ Panellists were unaware of the samples they tasted (samples were labelled with codes for identification). The samples were selected from commercially important Greek wines, including all the margins of price for Greek wines and representing diversity from different varieties and vintages. The sensory evaluation was based on a $0-100$ scale (<60: unacceptable, 100: excellent). Sensory evaluation was carried out in triplicate in order to evaluate separately aroma, taste, and overall sensory quality. Bottles were stored in a special freezer (Eurocave, France) at $16^{\circ} \mathrm{C}$ prior to organoleptic testing, and the samples $(50 \mathrm{~mL})$ were presented in standardized Institut National d'Appellation d'Origine-type glasses.

\section{Economic evaluation of the investment and operation costs}

Investment and operation costs were based on the average commercial costs for machinery and consumables and on the average labor cost in the EU.

\section{Statistical analysis}

Regression analysis and PCA were used to estimate the price of the experimental wines and subsequently to rank the experimental and commercial wines that are available in the Greek market based on their sensory quality and price. Multiple regression analysis was used to determine whether sensory quality and wine age affected wine price. Statistical data were computed using the Statistical Package for the Social Sciences (SPSS) program, Version 11.0 (SPSS Inc., Chicago, IL, USA). 


\section{Results and discussion}

Because the use of immobilized cells on dried raisin berries resulted in improved sensory quality characteristics, ${ }^{6}$ the strategy adopted in the present study was to compare results obtained by application of simple and exponential regression analysis, as well as PCA, for price estimation of the novel wines. Additionally, the factors affecting wine price and sensory quality were of interest. At a second stage, investment and operation costs (in total defined as production cost) for the industrial application of the proposed technology were evaluated.

\section{Price estimation of red wines produced by immobilized cells}

In order to correlate wine sensory quality with price in a given market, 15 commercially important and well-known Greek wines and two red wines produced by free and immobilized cells on raisin berries, respectively, were used in the present study.

The encoded wine samples, their price, and the results of the sensory evaluation are presented in Table 1. Linear regression analysis based on price as the dependent variable and sensory quality rating as the independent variable resulted in a rather low value of $R^{2}(0.689)$, indicating that $68.9 \%$ of the variance price accounted for sensory evaluation. Linear regression was significant at $P<0.0001$. Other factors that might affect wine price are extrinsic factors such as reputation, region, appellation d'origine, and critics' opinions, which are difficult to estimate. Linear regression analysis enabled the creation of the following equations and prediction of prices for the two experimental wines based on their sensory quality ratings ( 80.0 and 77.5 for wine produced by immobilized and free cells, respectively):

Predicted price of wine code 16 (produced by immobilized cells):

$$
-€ 41.576+€ 0.673 * 80=€ 12.26
$$

Predicted price of wine code 17 (produced by free cells):

$$
-€ 41.576+€ 0.673 * 77.5=€ 10.58
$$

The significant difference $(P<0.05)$ in sensory quality between the two wines produced by two different biotechnological processes could be quantified and expressed as difference in their price $€ 12.26-€ 10.58=€ 1.68$.

From the linear regression equation, it was possible to predict the prices for commercial wines and the corresponding value, which was the difference between predicted and true (commercial) price. Then, ranking of the wines that were tasted was based on the relation between sensory quality and price by placing them in order of decreasing value. The results are shown in Table 1 and Figure 1. The further a wine is located from the regression line to the right (eg, wine codes 7, 6, 9, and 8) (Figure 1), the better the sensory quality-price correlation. Based on the same correlation for the two experimental wines (wine codes 16 and 17), it is clear that the difference in price should correspond to the difference in sensory quality.

Regression analysis based on the exponential model price $=\exp (\mathrm{a}+\mathrm{b} *$ quality $)$ resulted in a 75.3 value of $R^{2}$, indicating that $75.3 \%$ of the variance price accounted for sensory evaluation. Exponential regression analysis was significant at $P<0.0001$. This model explained better our results mainly for high- and low-price wines, giving for sensory quality 0 about a price of $€ 0$ ( $€ 0.06)$. As previously described, it was possible to predict the corresponding value of the commercial wines and rank the wines based on sensory quality and price relationship (Table 1).

PCA is a technique that may be used to represent and visualize relationships among interrelated variables. Even if it is most frequently used to decrease data dimensionality, it is possible to retain all the information presented in the original data without this reduction. The two factors accounted for $100 \%(91.4+8.6)$ (Figure 2$)$ of the total variance. The small angle between the vectors in the component plot, representing sensory quality and price, indicates that these factors are positively correlated. As shown in Figure 2, a ranking axis for the correlation between sensory quality and price was also created. This axis is actually the bisector of the angle between the two vectors, ie, the vector of price and the vector of sensory quality. It is clear that the wine that would follow the optimum correlation between sensory quality and price would be of the highest quality and lowest price. The projection of such a wine on the ranking axis would have been located at the very high point (upper part of the axis). For example, wine code 1 had the higher projection from all wines and therefore the optimum correlation between sensory quality and price, whereas wine code 13 had the lowest projection and thus the worst correlation. In order to estimate the commercial price in the same market for the two experimental wines, the prices corresponding to the PCA-based model were calculated so as to follow the same wine-ranking process (Figure 2). Considering that sensory quality ratings for the wines produced by immobilized yeast on dried raisin berries (wine code 16) and free cells (wine code 17) were 80.0 and 77.5 , respectively, the corresponding 


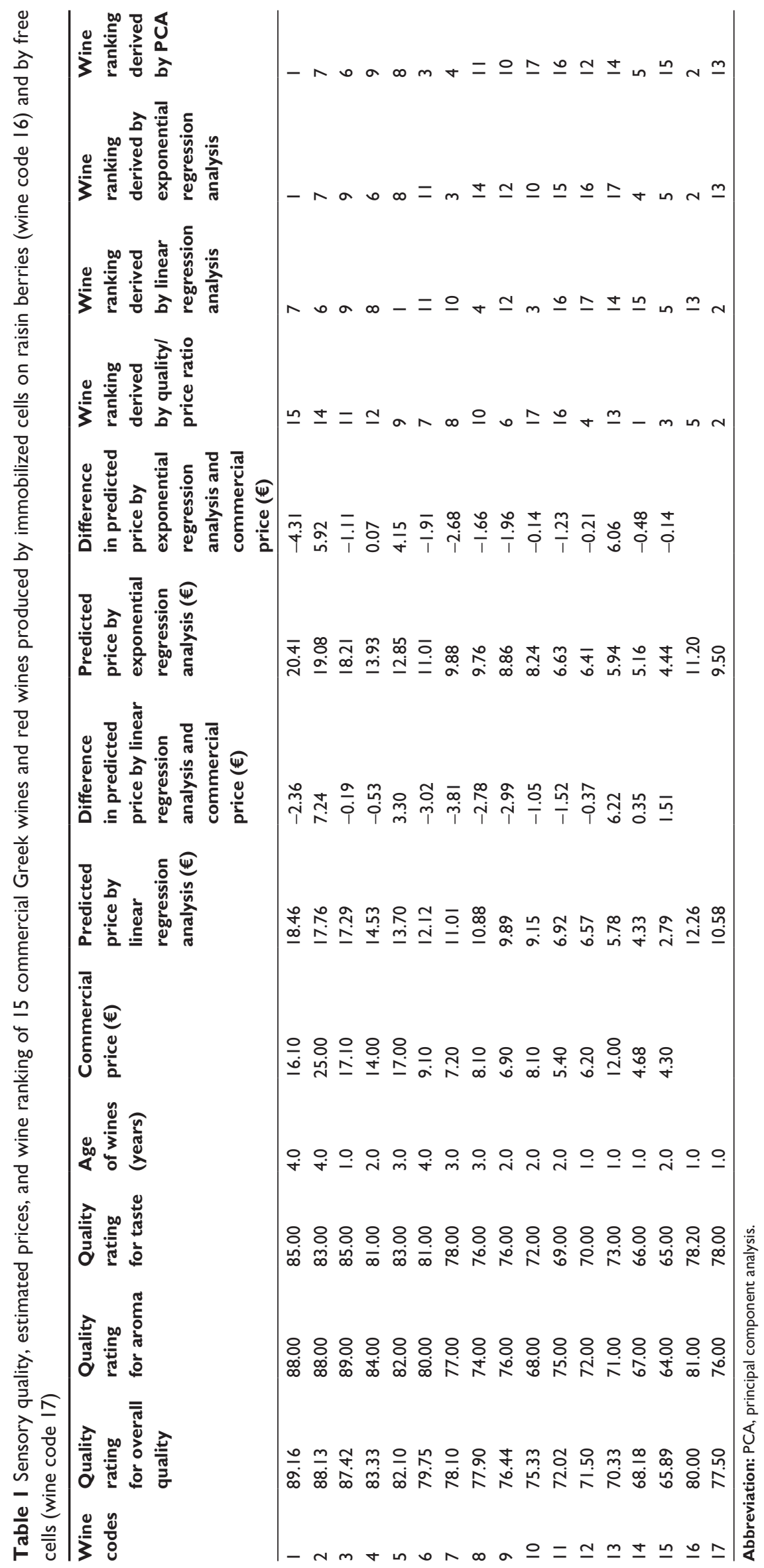




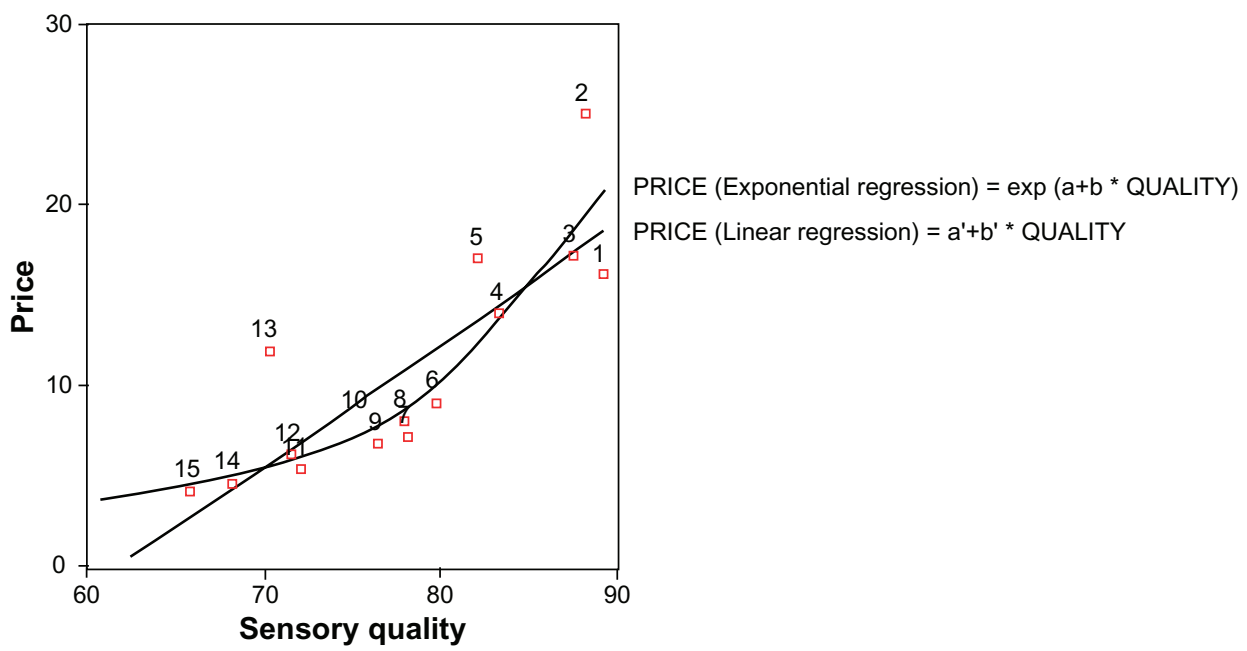

Figure I Wine ranking based on regression analysis of sensory quality and price of I 5 commercial Greek wines.

prices would have been $€ 12.66$ and $€ 10.58$, in order to follow a balanced correlation between quality and price. The prices of the two experimental wines have been estimated taking into consideration that both projections on the ranking axis (bisector line) should be near to the intersection point of the two vectors (vector of price and vector of sensory quality), in order to be based on the wines of interim correlation between sensory quality and price (excluding wines of optimum and worst correlation). Hence, the significant difference $(P<0.05)$ in sensory quality between the two wines produced by two different biotechnological processes could be quantified and expressed as difference in price. The difference in price

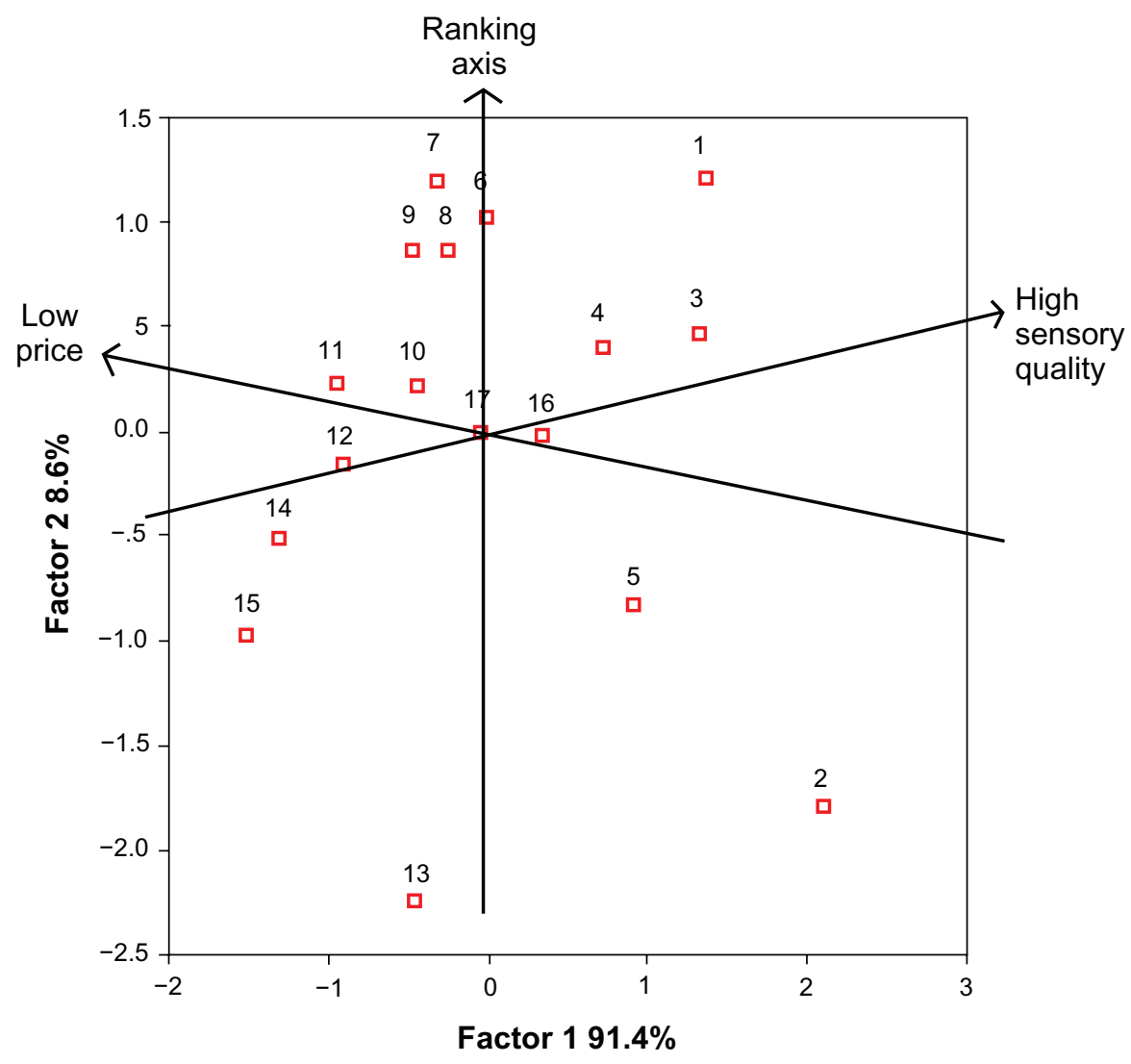

Figure 2 Wine ranking based on the correlation of sensory quality and price by principal component analysis of 15 commercial Greek wines and red wines produced by immobilized cells on raisin berries (wine code 16) and by free cells (wine code 17). 
was $€ 12.66-€ 10.58=€ 2.08$ instead of $€ 1.68$, as predicted from linear regression, and $€ 11.20-€ 9.50=€ 1.70$, as predicted from exponential regression analysis. Also observed was a slightly different ranking from that corresponding to regression analysis (Table 1). Although the use of regression analysis was easier, PCA provided improved results because simple regression and exponential regression analysis represent a part of the relationship between the two variables (68.4\% and 75.3\%, respectively), whereas with PCA the total variance explained by the two components was $100 \%$.

Another approach to correlate sensory quality with price would have been a division of these two variables (Table 1). However, such a correlation would have favored low-price wines and would be unfair for wines of high sensory quality and price. The inaccuracy of the above approach is due to the fact that sensory quality and price follow different increment rates, as other factors also interfere that are not estimated by regression analysis. The use of PCA and regression analysis revealed completely different results from a simple division of sensory quality evaluation by price. For example, although wine code 15 appears as a wine with a better correlation between sensory quality and price compared with wine code 1 when simply calculating the sensory quality/price ratio, the opposite results were obtained when PCA analysis was applied (Table 1). Processing of results by PCA seemed more accurate because the overall sensory quality ratings and prices of all wines were considered, whereas comparison based on only sensory quality ratings divided by wine price took into account each sample separately.

We also tried to investigate whether sensory quality and wine age had a significant effect on wine price, and PCA revealed that wine price is mainly affected by sensory quality rather than wine age, as the axis corresponding to sensory quality is closer to the price axis than the wine age axis (Figure 3 ). Using multiple regression analysis and considering price as the dependent variable, with sensory quality and wine age as the independent variables, it was concluded that wine age had no effect on wine price $(\operatorname{sig}=0.959)$ in the Greek market. At this point, it is worth mentioning that age of all commercial wines used in the present study ranged 1-4 years. Therefore, the estimated price of the experimental wines is not expected to change significantly after $3-4$ years of aging.

In order to evaluate the effect of aroma and taste on overall sensory quality, linear regression analysis was applied based on overall sensory quality being the dependent variable, and aroma and taste being the independent variables. The analysis resulted in a rather high $R^{2}(0.945)$, indicating that $94.5 \%$ of

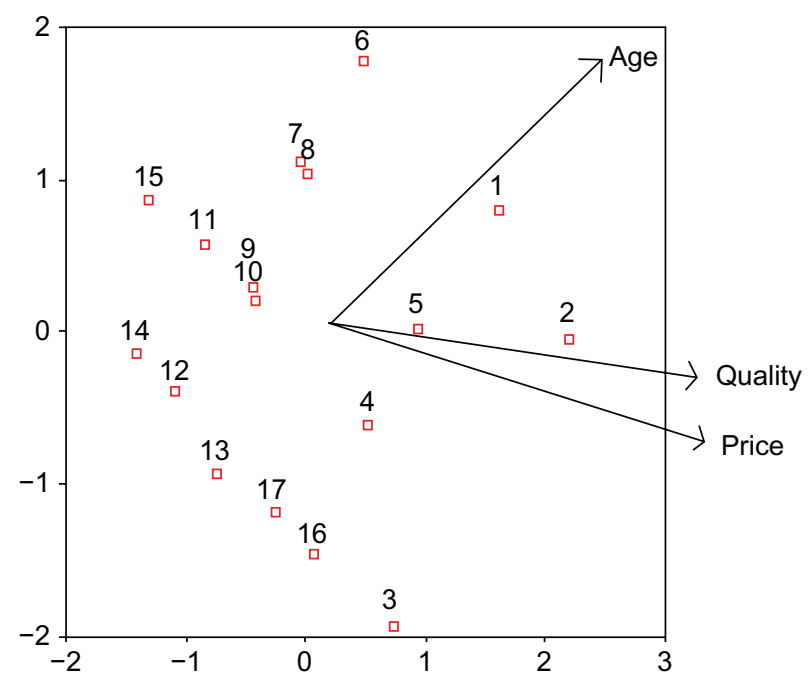

Figure 3 Correlation of sensory quality, price, and age by principal component analysis of 15 commercial Greek wines and red wines produced by immobilized cells on raisin berries (wine code 16) and by free cells (wine code 17).

the variance of overall sensory quality was explained by the two predictor variables (aroma and taste). Linear regression analysis was significant at $P<0.0001$. Other factors that might have affected overall sensory quality were color and appearance. Linear regression analysis enabled the creation of the following regression equation:

$$
\begin{aligned}
\text { Overall sensory quality }= & 1.733+0.421 * \text { aroma } \\
& +0.571 * \text { taste }
\end{aligned}
$$

Thus, it can be concluded that, for red wines, taste was more important than aroma. By this method, an estimation of the importance in score for the wine sensory quality evaluation was possible, which previously was based on empiric methods. Although red wines produced by immobilized cells on raisin berries and by free cells did not significantly differ in taste (Table 1), the aroma of the former was significantly improved according to the sensory evaluation.

\section{Estimation of the investment and operation costs of red wines produced by immobilized cells}

For industrial application of the proposed technology, the additional necessary equipment consists of i) a stainless steel net located at the fermentor for separating the skins from the immobilized cells and ii) an additional door at the upper part of the fermentor for the addition and removal of the skins. ${ }^{6}$

The increase of the investment cost was estimated to be $€ 3,500$ (the cost for a 20,000 - $\mathrm{L}$ fermentor is raised from $€ 13,000$ to $€ 16,500)$. Considering at least three wine fermentations annually, each producing 10,000-L of wine 
and having an investment period of 5 years, the increased investment cost was estimated to be $(€ 16,500-€ 13,000) /$ $(3 * 5 * 10,000) \approx € 0.023 / \mathrm{L}$.

The increase of the operation cost, which is the immobilization support, is due to the cost of the dried raisin berries and is estimated to be $€ 600$. Therefore, the annual increased operation cost was estimated to be $€ 600 /(3 * 10,000)=€ 0.02 / \mathrm{L}$, as the same immobilized biocatalyst could be used in the three repeated batch fermentations. Of note, neglible costs associated with disposal of spent berries, preparation of immobilized biocatalysts, and changes in the industrial process were not taken into consideration.

The total increase of the production cost (including both investment and operation costs) was estimated to be $€ 0.023+€ 0.020=€ 0.043 / \mathrm{L}$ or $€ 0.043 * € 0.75=€ 0.032 /$ bottle, which is significantly lower than the increased price $(€ 2.08)$ estimated per bottle. Taking into account that the price of wine sold by the manufacturer is almost half the retail commercial price, the profit for the wine industry is estimated to be $(€ 2.08-€ 0.032) / 2=€ 1.02 /$ bottle.

\section{Conclusions}

Using the appropriate statistical tool, it was possible to estimate the price of red wines produced by immobilized cells on dried raisin berries by correlating sensory quality and price in a given market. Although no significant differences were observed in taste, the aroma of red wines produced by the immobilized cells was improved compared with wine produced by free cells. However, it seemed that taste was more important than aroma in determining sensory quality, and wine price was mainly affected by sensory quality rather than wine age in the Greek market. The estimated higher price of wine produced by immobilized cells compared with wine produced by free cells corresponded to improved sensory quality and was sufficient to counterbalance the increased investment and operation costs owing to industrial application of the immobilized cell technology. The proposed approach might also be expanded to other products.

\section{Disclosure}

The authors report no conflict of interest.

\section{References}

1. Margaritis A, Merchant FJA. Advances in ethanol production using immobilized cell systems. CRC Crit Rev Biotechnol. 1984;1: 33-9393.

2. Stewart GG, Russell I. One hundred years of yeast research and development in the brewing industry. J Inst Brew. 1986;92: $537-558$.
3. Kourkoutas Y, Komaitis M, Koutinas AA, Kanellaki M. Wine production using yeast immobilized on apple pieces at low and room temperatures. J Agric Food Chem. 2001; 49:1417-1425.

4. Kourkoutas Y, Koutinas AA, Kanellaki M, et al. Continuous wine fermentation using a psychrophilic yeast immobilized on apple cuts at different temperatures. Food Microbiol. 2002;19:127-134.

5. Kourkoutas Y, Komaitis M, Koutinas AA, et al. Wine production using yeast immobilized on quince biocatalyst at temperatures between 30 and $0^{\circ}$ C. Food Chem. 2003;82:353-360.

6. Tsakiris A, Sipsas V, Bekatorou A, et al. Red wine making by immobilized cells and influence on volatile composition. J Agric Food Chem. 2004;52:1357-1363.

7. Günata YZ, Bayonove C, Baumes R, Cordonnier C. The aroma of grapes. Localisation and evolution of free and bound fractions of some grape aroma components cv Muscat during first development and maturation. J Sci Food Agric. 1985;36:857-862.

8. Dubourdieu D, Olivier C, Boidron J. Incidence des opérations prefermentaires sur la composition chimique et les qualités organoleptiques des vins blancs sec. Connaiss Vigne Vin. 1986;20:53-76.

9. Suomalainen H, Lehtonen $\mathrm{M}$. The production of aroma compounds by yeast. J Inst Brew. 1979;85:149-156.

10. Jackson DJ, Lombard PB. Environmental and management practices affecting grape composition and wine quality. Am J Enol Vitic. 1993; 44:409-430.

11. Peynaud E. Connaissance et travail du vin. Dunod: Paris; 1975.

12. Amerine M, Roessler E. Wines: their sensory evaluation. W. H. Feeman and Company: New York, USA;1983.

13. Verdú Jover AJ, Lloréns Montes FJ, Del Mar Fuentes Fuentes M. Measuring perceptions of quality in food products: the case of red wine. Food Qual Pref. 2004;15:453-469.

14. Goldstein R, Almenberg J, Dreber A, et al. Do More Expensive Wines Taste Better? American Association of Wine Economists. No 16, April 18, 2008. http://www.wine-economics.org/workingpapers/ AAWE_WP16.pdf. Accessed 2011 Jan 4.

15. Lockshin L, Jarvis W, d' Hauteville F, Perrouty J-P. Using simulations from discrete choice experiments to measure consumer sensitivity to brand, region, price, and awards in wine choice. Food Qual Pref. 2006;17:166-178.

16. Brochet F. Chemical Object Representation in the Field of Consciousness. Working paper. General Oenology Laboratory. Talence, France;2001.

17. Plassmann H, O’ Doherty J, Shiv B, Rangel A. Marketing actions can modulate neural representations of experienced pleasantness. Proc Nat Ac Sci. 2008;105:1050-1054.

18. Teil G. La production du jugement esthétique sur les vins par la critique vinicole. Sociologie du Travail. 2001;43:67-89.

19. Combris P, Lecocq S, Visser M. Estimates of a hedonic price equation for Bordeaux wine: does quality matter? Econ J. 1997;107:390-402.

20. Combris P, Lecocq S, Visser M. Estimation of a hedonic equation for Burgundy wine. Appl Econ. 2000;32:961-967.

21. Landon S, Smith CE. The use of quality and reputation indicators by consumers: the case of Bordeaux wine. J Cons Pol. 1997;20:289-323.

22. Ling B-H, Lockshin L. Components wine prices for Australian wine: how winery reputation, wine quality, region, vintage, and winery size contribute to the price of varietal wines. Aust Mark J. 2001;11: 19-32.

23. Nerlove M. Hedonic price functions and the measurement of preference: the case of Swedish wine consumers. Eur Econ Rev. 1995; 39:1697-1716.

24. Oczkowski E. A hedonic price function for Australian premium table wine. Austr J Agric Econ. 1994;38:93-110.

25. Oczkowski E. Hedonic wine price functions and measurement error. Econ Rec. 2001;77:374-382.

26. Unwin T. Hedonic indexes and the qualities of wines. JWine Res. 1999; 10:95-104.

27. Faliqué E, Fernádez E, Dubourdieu D. Differentiation of white wines by their aromatic index. Talanta. 2001;54:271-281. 
28. Koussissi E, Paterson A, Piggott JR. Flavour discrimination of Greek dry red wines. J Sci Food Agric. 2003;83:797-808.

29. McEwan JA, Hunter EA, van Gemert LJ, Lea P. Proficiency testing for sensory profile panels: measuring panel performance. Food Qual Pref. 2002;13:181-190.

30. Legin A, Rudnitskaya A, Lvova L, et al. Evaluation of Italian wine by the electronic tongue: recognition, quantitative analysis and correlation with human sensory perception. Anal Chim Acta. 2003;484:33-44.
31. Tsakiris A, Kourkoutas Y, Dourtoglou DJ, et al. Wines produced by immobilized cells on dried raisin berries in sensory evaluation comparison with commercial products. J Sci Food Agric. 2006;86: 539-543.

32. Zamora MC, Guírao M. Analysing the contribution of orally perceived attributes to the flavor of wine. Food Qual Pref. 2002;13:275-283.

\section{Publish your work in this journal}

The International Journal of Wine Research is an international, peer-reviewed open-access, online journal focusing on all scientific aspects of wine, including: vine growing; wine elaboration; human interaction with wine; and health aspects of wine. The journal provides an open access platform for the reporting of evidence based studies on these topics. The manuscript management system is completely online and includes a very quick and fair peer-review system, which is all easy to use. Visit http://www.dovepress.com/testimonials.php to read real quotes from some of our published authors. 